\title{
ASPECTOS HISTÓRICOS DO POVO INDÍGENA KRAHÔ: UM BREVE RELATO SOBRE O CONTATO COM A SOCIEDADE BRASILEIRA
}

\author{
MARTA VIRGINIA DE ARAÚJO BATISTA ABREU ${ }^{1}$ \\ UFT \\ FRANCISCO EDVIGES ALBUQUERQUE ${ }^{2}$ \\ $U F T$
}

\begin{abstract}
RESUMO: Este trabalho tem como objetivo apresentar a sociedade krahô, sua história e seus aspectos culturais. Faremos considerações acerca da história do contato dos indígenas krahô com a sociedade brasileira, para então compreendermos as consequências do contato para a realidade desse povo. Como fundamentação teórica, foi citado, dentre outros, o autor Melatti (1967). Os estudos apontam que a sociedade krahô tenta resistir às influências culturais, mantendo suas atividades culturais e seus saberes tradicionais. Espera-se que este trabalho possa contribuir para divulgação da história do povo krahô, bem como sua cultura.
\end{abstract}

PALAVRAS-CHAVE: povo krahô; história do povo krahô; cultura do povo krahô.

\section{Historic aspects of the Krahô indigenous people: a brief account of the contact with Brazilian society}

ABSTRACT: This work aims to present the Krahô society, its history and its cultural aspects. We will consider the history of the Krahô Indians' contact with Brazilian society, and then understand the consequences of the contact for the reality of this people. As theoretical foundation, Melatti (1967) was cited, among others. Our studies show that Krahô society has tried to resist cultural influences, maintaining its cultural activities and its traditional knowledge. We expect this work to contribute to the dissemination of the history of the Krahô people, as well as their culture.

KEYORDS: Krahô; history of the Krahô; culture of the Krahô.

\footnotetext{
${ }^{1}$ Possui mestrado em Letras: Ensino de Línguas pela Universidade Federal do Tocantins (2012). E-mail: martavirginia@mail.uft.edu.br.

${ }^{2}$ Professor Associado II da Universidade Federal do Tocantins/UFT - Campus de Araguaína. Possui mestrado em Letras e Linguística pela Universidade Federal de Goiás (1999) e Doutorado em Letras pela Universidade Federal Fluminense (2007). Realizou o Estágio Pós-doutoral sobre Os Aspectos Morfossintáticos Apinayé(Jê), na Universidade de Brasília-UNB. E-mail: fedviges@uol.com.br .
} 


\section{Introdução}

Nesse trabalho retratou-se sobre o povo krahô, sua cultura e sua história. Buscou-se fazer um pequeno histórico do contato dos indígenas krahô com a sociedade majoritária. O objetivo principal de nosso trabalho foi apresentar a sociedade krahô, sua história e seus aspectos culturais. Os Krahô habitam entre os rios Manoel Alves Grande e Manoel Alves Pequeno, afluentes da margem direita do Rio Tocantins. A Terra Indígena Kraholândia foi homologada pelo Decreto-Lei $\mathrm{n}^{\circ}$ 99.062, de 7 de março de 1990 e fica localizada entre os municípios de Goiatins e Itacajá, no noroeste do estado do Tocantins. A Terra Indígena Kraholândia tem uma extensão de 320 mil hectares e fica entre as longitudes $46^{\circ} 54^{\prime} \mathrm{W}$ e $51^{\circ} 18^{\prime} \mathrm{W}$ e as latitudes $8^{\circ} \mathrm{S}$ e $9^{\circ} \mathrm{S}$. É composta por vinte e cinco aldeias, dentre as quais podemos destacar Manoel Alves, Pedra Branca, Forno Velho, Santa Cruz, Aldeia Nova, Bacuri, Serra Grande, Pedra Furada, Cachoeira, Galheiro, Rio Vermelho, Lagoinha, Morro do Boi e Mangabeira. Segundo dados da Fundação Nacional de Saúde (FUNASA, 2010), a população krahô é constituída de aproximadamente 2.463 indígenas.

\section{O povo Krahô}

A terra ocupada pelos Krahô tem como vegetação predominante o cerrado, porém há matas fechadas. As casas das aldeias krahô são organizadas de forma circular, sendo que há um caminho que sai de cada casa ao centro do pátio. A arquitetura das casas é semelhante à do restante da população regional: são feitas, em sua maioria, de palha de palmeira e rebocada com barro, desenhada no modelo de duas águas, sem janelas e sem divisão no seu interior.

O povo krahô sobrevive da produção de mandioca, milho, banana, arroz, fava, feijão, inhame, abóbora, dentre outros. Estes indígenas 
plantam, ainda, urucum, cabaça e algodão. Eles criam porcos, galinhas e também utilizam a caça para completar a alimentação. As caçadas são realizadas individualmente ou em grupos e estas acontecem geralmente no período da seca. Ultimamente as caçadas têm sido menos frequentes devido à escassez de animais.

O povo krahô fabrica muitos artefatos e dentre os mais conhecidos temos as cestas, pulseiras, bolsas, brincos e colares. As palhas de coqueiro e sementes variadas do cerrado são os materiais utilizados na produção desses artefatos.

Entre os Krahô existem várias associações com sede em diversas aldeias. Dentre essas associações, podemos citar a Associação Mãkrare, que foi fundada em 1988 e fica situada na Aldeia Nova. Dessa associação fazem parte também as aldeias Serra Grande e Lagoinha. Há também a Kapéj, associação civil sem fins lucrativos, que fica situada dentro da terra indígena e é composta pela maioria das aldeias krahô. Outra associação atuante entre os Krahô é a Aukêré, que foi fundada em 2003, situa-se na aldeia Cachoeira e contribuiu imensamente na apresentação de projetos que beneficiam o povo krahô dessa aldeia.

Há, ainda, as associações Wôkrã situada na aldeia Rio Vermelho; a Inxêcati, que reúne todas as aldeias krahô localizadas ao sul do Riozinho, a Kyiré, na Pedra Branca, e também a Wyty-Catë, que fica situada em Carolina, estado do Maranhão. Nessas associações os indígenas krahô discutem sobre os problemas encontrados nas aldeias e organizam-se para poderem alcançar suas reivindicações e lutar pelos seus direitos. São organizadas, por essas associações, feiras de sementes que têm como objetivo divulgar e distribuir as sementes que estão sendo plantadas em terras indígenas krahô.

A seguir, encontra-se a localização da Terra Indígena Krahô, mais conhecida como Kraholândia. 
Figura 1. Localização da Área Indígena Krahô.

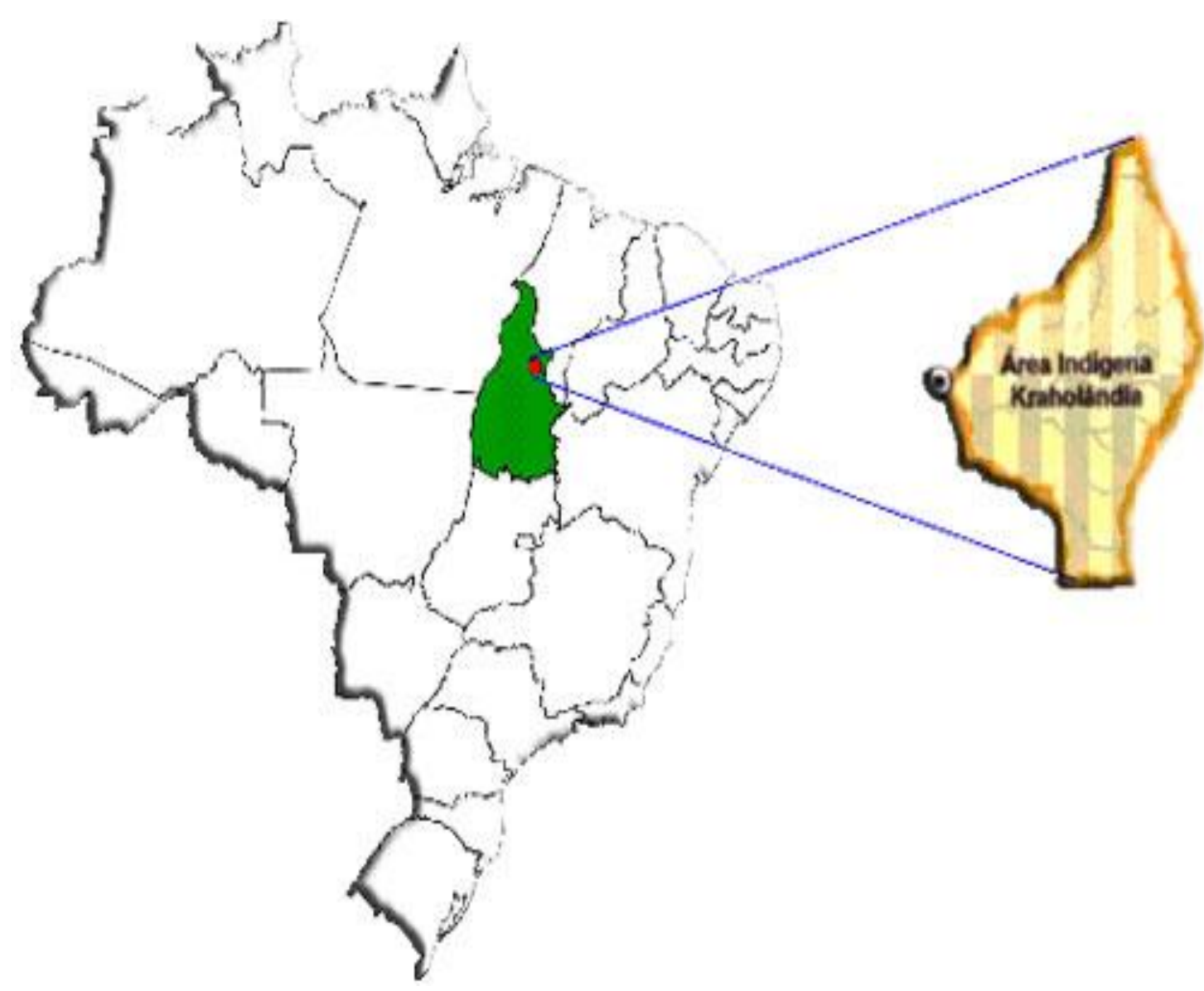

Fonte: Centro de Trabalho Indigenista (2012).

Melatti (1967) afirma que há cerca de cinquenta rituais e cerimônias dentre as festas realizadas pelos Krahô, entretanto, algumas há muitos anos não são realizadas. Os Krahô, de modo geral, gostam de realizar festas e aproveitam esses momentos também para se confraternizarem com os indígenas das outras aldeias.

A sociedade krahô é dividida em duas metades sazonais: Catàmjê, que está relacionada ao período chuvoso (inverno) e ocupa o lado oeste do pátio e Wacmêjê que está relacionada ao período da seca (verão) e, por sua vez, ocupa o lado leste do pátio. Segundo Melatti (1967, p. 65), a escolha do nome é que determinará a qual metade o indivíduo fará parte, sendo que existe uma lista de nomes pessoais pertencente a cada metade. Toda pessoa do gênero masculino, ao nascer, ganha o nome de 
um irmão de sua mãe ou mesmo de outro parente de sua mãe. Enquanto que as pessoas do gênero feminino ganham o nome de uma irmã do pai ou de outro parente de seu pai. As metades Catàmjê e Wacmêjê têm funções importantes dentro dos cerimoniais como também no dia a dia na aldeia. De acordo com Melatti (1967, p. 64), os homens da metade Catàmjê, ao iniciar o período da seca, elegem dois homens para serem prefeitos durante essa estação que compreende seis meses. Esses indivíduos possuem várias tarefas para realizar durante o dia na aldeia e orientam, ainda, os outros indígenas sobre o que estes também devem fazer. Quando inicia o período chuvoso, é a vez dos homens da metade Wacmêjê elegerem novos prefeitos para governar durante seis meses e que vão desenvolver as mesmas atividades que a outra metade desempenhou durante a estação da seca.

\section{Contato dos Krahô com a sociedade brasileira}

O contato de duas sociedades de culturas diferentes pode causar intensos conflitos, como disputas entre si e também mudanças culturais. O contato da sociedade brasileira com a sociedade indígena ocasiona inúmeras alterações, principalmente, para a sociedade indígena. Essas mudanças podem ter consequências positivas ou negativas em vários aspectos, tais como: conflitos de identidade, relações de trabalho, hábitos alimentares, condições de saúde, aspectos econômicos, educação formal, concepções religiosas, dentre outros.

Sobre o contato dos Krahô com a sociedade brasileira, Melatti (1967, p. 15) afirma que esse contato interétnico se deu por volta de 200 anos. O contato ocorreu em uma área entre a divisa do estado do Maranhão com o Goiás. Essa área ficava situada entre os rios Tocantins, Farinha, Alto-Itapecuru, Parnaíba, Perdido e Sono, sendo espaços que não forneciam especiarias ou minerais preciosos, mas ofereciam vantagens aos criadores de gado daquela região. Nessas áreas havia duas frentes de povoamento vindas do Maranhão e do Pará que eram de 
tipo agrícola; e da Bahia que era do tipo pastoril. Essas frentes tinham por objetivo a exploração econômica das áreas em torno desses rios.

A frente agrícola, conforme Melatti (1967, p. 15), ocupava as margens do Rio Tocantins perto da sua foz, o entorno de Belém, o vale de Guamá, o norte do Pará e do Maranhão, o Vale do Itapecuru e Caxias. Apesar dessa frente agrícola não ter muito interesse na área ocupada pelos Krahô, por ser uma área sem grandes florestas, o que não era interessante para o cultivo de arroz e algodão, o contato interétnico dos Krahô teve sérias consequências decorrentes disso.

Entretanto, a frente pastoril, caracterizada pela pecuária, merece destaque no que concerne ao contato dos indígenas Krahô com a sociedade brasileira. De acordo com Melatti (1967, p. 19), no Brasil Colonial, a criação de gado no Nordeste Brasileiro teve origem na Bahia e em Pernambuco. O gado do estado do Pernambuco tomou toda a costa da Paraíba e do Rio Grande do Norte e seguiu para o estado do Ceará. O gado baiano foi conduzido até o rio São Francisco, juntamente com o gado pernambucano e chegaram até ao rio Parnaíba. Por volta do ano de 1730, após atravessar este rio, adentraram ao estado do Maranhão e lá tiveram o primeiro contato com o povo krahô.

Cumpre ressaltar que a frente agrícola cercava os povos indígenas pelo norte e nordeste e a frente pastoril cercava-os pelo leste e pelo sul. Segundo Melatti (1967, p. 19) esses povos eram os Gamelas, Tupis, Timbiras (Txokamekra, Canela, Krahô, Pikóbye) e os Akwẽ (Xerente e Xavante). Aos poucos essas frentes foram ocupando a área que restava para os indígenas. Portanto, para que esses povos indígenas pudessem escapar aos ataques, eles fugiram para o oeste e tiveram que disputar terras com outros povos indígenas. Porém, com o aumento da navegação no rio Tocantins, essa saída para o oeste ficou mais difícil. Vale destacar que o rio Tocantins teve imensa importância no contato dos indígenas com a sociedade brasileira, por ter sido um grande 
recurso de ligação entre a área pastoril e a área agrícola, situadas no norte de Goiás e no Pará, respectivamente.

Melatti (1967, p. 27) afirma que para que possamos entender melhor a situação dos Krahô quando eles tiveram contato com a sociedade brasileira, é preciso que sejam apresentadas as características da área pastoril e da área agrícola. O autor destaca que mesmo os Krahô não tendo contato mais próximo com a frente agrícola, é importante fazermos algumas considerações a este respeito, para que se possa compreender a relação existente entre essas duas frentes e o deslocamento da mão-de-obra.

A primeira característica da área pastoril é sua baixa densidade demográfica. Isso acontecia porque o gado era criado alimentando-se apenas da vegetação nativa e, sendo que esta era de fraco valor nutritivo, eram necessários muitos hectares de pasto para manter esse gado. Por isso, um grande número de gado poderia ser cuidado por apenas uma pessoa. Outra característica da frente pastoril, diferentemente da frente agrícola, era emprego de mão de obra livre, sem o uso de mão de obra escrava. Como vimos anteriormente, a área pastoril não utilizava grande número de mão de obra, por isso era fácil encontrar um número suficiente de mão de obra livre. A terceira característica da área pastoril também entra em contraste com a área agrícola. Enquanto esta era dividida em senhores e escravos, aquela matinha uma relação de compensação pelo trabalho exercido e com oportunidade de melhoria considerável. Entretanto, para que esses vaqueiros pudessem ter essa ascensão, as fazendas tinham que conquistar mais espaços. Esses espaços eram tomados dos indígenas.

A esse respeito, Melatti (1967, p. 32) afirma que, para as frentes agrícola e pastoril, os indígenas eram empecilhos para expansão de seus territórios, pois os indígenas eram os proprietários das terras que eles precisavam. Embora a frente pastoril tentasse se livrar dos indígenas, por não necessitarem do trabalho deles, a frente agrícola tentava utilizar-se dessa mão de obra, logo após terem sidos tirados do 
seu meio ou serem pacificados. Pohl (1976, p. 125) também relata sobre o uso de indígenas como mão de obra nessa região. Esse autor nos assegura que, como forma de conseguirem trabalhadores braçais para suas atividades, os fazendeiros se valiam da lei, que na época permitia que fossem tratados como escravos os indígenas capturados em guerra. Eles ainda usavam como pretexto a disseminação da doutrina religiosa cristã, para poderem adentrar as matas e aprisionarem indígenas.

Melatti (1967, p. 33), relatando sobre o contato dos indígenas krahô, afirma que estes fizeram um acordo com os criadores de gado. Os Krahô não foram utilizados para o trabalho na pecuária, eles continuaram desenvolvendo suas atividades normalmente, porém para que estes pudessem viver em paz, eles deveriam ajudar a sociedade pastoril na guerra contra os outros Timbiras e contra os Akwẽ, para então apossarem-se das terras deles.

De modo geral, todos os povos indígenas Gamelas, Tupis, Timbiras (Txokamekra, Canela, Krahô, Pikóbye) e os Akwẽ (Xerente e Xavante) tiveram conflito com os povos da sociedade brasileira. Melatti (1967, p. 34) aponta que, por causa do grande avanço da frente pastoril, os indígenas krahô deram trégua e começaram a lutar por novos territórios. Contudo, frequentemente eles ainda realizavam ataques àquelas terras das quais eles tinham sido retirados. Essa luta com os criadores de gado obrigaram os Krahô a se mudarem e se refugiarem no ocidente, mais precisamente próximo ao rio Tocantins. Os indígenas krahô fixaram habitação a cinco léguas de São Pedro de Alcântara (hoje Carolina - MA).

Ao chegarem a esse território, por volta do ano 1813, os Krahô fizeram amizade com fazendeiros de grande prestígio na região de São Pedro de Alcântara. A partir de então, os indígenas krahô tornaram-se intrumentos para que os criadores de gado pudessem apossarem-se de mais terras e, assim, aumentarem as fazendas desses criadores. De acordo com Melatti (1967, p. 42), na segunda década do século XIX, os 
indígenas krahô deixaram as aldeias que moravam e foram residir bem próximo a São Pedro de Alcântara. O número de indígenas krahô que se deslocaram chegava a três mil e eram comandados por um chefe e sete cabos de guerra.

Melatti (1967, p. 43) nos assegura que naquela época a frente pastoril ainda avançava sobre as terras indígenas, e ainda tinha o povo krahô como forte aliado. Os indígenas krahô continuavam se dirigindo ao povo akwẽ, pois o restante do povo timbira já não oferecia ameaça ou resistência aos Krahô. Com isso, os fazendeiros não tinham mais interesse em manter o povo krahô como aliado e, dessa forma, foi projetada uma maneira de afastá-los da área pastoril, isolando-os juntos com os Akwẽ no povoamento de São Fernando, foz do rio do Sono. Aos poucos a aliança com a sociedade brasielira sofreu alterações e os conflitos contra os outros indígenas cessaram.

Para satisfazer a vontade dos fazendeiros, em 1848 o governo do Império criou o aldeamento de Pedro Afonso ${ }^{3}$. Nessa época, o governo do Império enviou o missionário Frei Rafael de Taggia para catequisar os indígenas krahô e xerente. Então os indígenas krahô foram transferidos para o aldeamento de Pedro Afonso e os xerente, para o de Teresa Cristina (hoje Tocantínia). Entretanto, a missão religiosa não obteve muito êxito; apesar dos indígenas terem uma boa relação com o Frei Rafael, não assimilaram bem a religião católica. Segundo Melatti (1967, p. 45), até hoje não houve nenhum outro representante dessa religião habitando entre os Krahô, mas apenas algumas visitas de missionários católicos.

Já no final do século XIX, o missionário protestante William Azel Cook visitou o povo krahô, depois que eles mudaram para as margens do rio Manoel Alves Pequeno. Ele chegou a percorrer pelas aldeias Gameleira e Serrinha com o objetivo de consultar os indígenas sobre a

\footnotetext{
${ }^{3}$ Os registros informam que os Krahô não habitavam a atual área urbana de Pedro Afonso, mas fixaram morada em três aldeias que ficavam a quatro léguas dessa cidade. Estima-se que havia cerca de 3 mil indígenas nessa época e que este número foi reduzido a apenas 620 indígenas, devido a epidemias que levaram muitos Krahô à morte.
} 
possibilidade de trazer um professor para aldeia, provavelmente com fins de evangelizar o povo krahô. A partir de 1925, a Missão Batista adentrou as aldeias krahô e trouxe o missionário Zacarias Campêlo, que instalou-se na aldeia Pedra Furada, permaneceu até 1935 e foi para as aldeia xerente. Outro missionário batista que esteve entre os Krahô foi Francisco Colares, que morou perto da aldeia Pedra Branca e ficou até 1940. Esse missionário foi quem transferiu a fazenda da Barriguda, que era distrito de Pedro Afonso, para Porto do Vau. Esse local ficava às margens do rio Manoel Alves Pequeno e a partir dele é que foi criado, em 1938, o núcleo urbano da Vila de Itacajá, atual cidade de Itacajá. Após a saída de Francisco Colares, os indígenas krahô passaram muito tempo ser ter uma missão religiosa entre eles.

Com o fim da aliança entre os indígenas krahô e os fazendeiros, iniciou-se uma relação conflituosa. Consta que, em 1940, os Krahô sofreram um ataque comandado por dois fazendeiros da região em que moravam. Segundo Melatti (1967, p. 48), calcula-se que morreram vinte e três indígenas nesse massacre. Alguns indígenas da aldeia Pedra Branca pressentiram o massacre e fugiram, que impediu que mais indígenas fossem mortos. O autor considera que o contato dos povos indígenas krahô com a sociedade nacional foi marcado profundamente por essa chacina. Por meio dela foram revelados quais eram as reais intenções daqueles fazendeiros não índios da região para com os indígenas, de quem anteriormente tinham se aproximaram. Por fim, a aliança entre os indígenas e os fazendeiros foi aniquilada, aproximando os indígenas krahô aos brasileiros, representados pelo Governo Federal.

É importante ressaltar que foi a partir daí que o Governo Federal se fez presente em terras indígenas por meio do Serviço de Proteção aos Índios (SPI). O assalto aos indígenas krahô repercutiu de forma generalizada e causou grande comoção por parte da população regional, o que motivou a realização de três ações importantes. A primeira, foi o julgamento e condenação dos responsáveis pelo massacre ou que tinham relação com o crime, que eram num total de setenta e duas 
pessoas. Outra ação foi a instalação do SPI nas terras krahô, que foi realizada com a ajuda de pessoas ligadas à Missão Batista. A terceira foi a doação de 320 mil hectares de terras ao povo krahô por meio do Decreto-lei $n^{\circ} 102$ de 5 de agosto de 1944.

\section{Considerações finais}

Após fazermos um estudo mais acurado sobre a história do contato dos indígenas krahô, podemos afirmar que o convívio destes com a frente pastoril foi o responsável pelo extermínio de muitos desses indígenas e que se esse convívio tivesse durado por mais tempo, os povos krahô poderiam ter sido drasticamente eliminados.

\section{Referências bibliográficas}

BANIWA, Gersen S. L. O índio brasileiro: o que você precisa saber sobre os povos indígenas no Brasil de hoje. Brasília: MEC/SECAD/ LACED/Museu Nacional, 2006.

CARNEIRO DA CUNHA, Manuela. Os mortos e os outros: uma análise do sistema funerário e da noção de pessoa entre os índios Krahô. São Paulo: Hucitec, 1978.

CTI, Centro de Trabalho Indigenista. 2012. Disponível em: HTTP://www.trabalhoindigenista.org.br . Acesso em: 15 jul. 2012.

FUNASA, Fundação Nacional de Saúde. RELATÓRIO DE GESTÃO 2010 SUEST/TO. Relatório. Palmas, 2010. Relatório.

LEITE, Yonne; SOARES, Maria Faço; SOUZA, Tânia Clemente de. O papel do aluno na alfabetização de grupos indígenas: a realidade psicológica das descrições linguísticas. In: OLIVEIRA, João Pacheco de (Org.). Sociedades indígenas e indigenismo no Brasil. Rio de Janeiro: Marco Zero, 1987. p. 127-138.

MELATTI, Julio Cezar. Índios e criadores: a situação dos Krahô na área pastoril do Tocantins. Rio de Janeiro: Instituto de Ciências Sociais da UFRJ, 1967.

O messianismo Krahô. São Paulo: Herder, 1972.

1974.

Reflexões sobre Algumas Narrativas Krahó. Série Antropologia, Brasília, n. 8, 
Ritos de uma tribo Timbira. São Paulo: Ática, 1978.

. O sistema de parentesco dos índios Krahô. In: MAYBURY-LEWIS, David; BARBENGER, Joan (Org.). Dialectial Societies. Cambridge: Harvard University Press, 1979. p. 46-79.

Curt Numuendajú e os Jê. Série Antropologia, Brasília, n. 49, 1985.

Índios do Brasil. Brasília: Editora da Universidade de Brasília, 1993.

MELIÁ, Bartomeu. Educação indígena e alfabetização. São Paulo: Loyola, 1979.

a

NIMUENDAJU, Curt. The eastern Timbira. Berkeley and Los Angeles: University of California Publications in American Archeology and Ethnology, 1946. v. 41

POHL, Johann Emanuel. Viagem no interior do Brasil. Belo Horizonte: Itatiaia/São Paulo: Ed. Da Universidade de São Paulo, 1976.

Recebido em: 28/11/2017 * Aprovado em: 17/06/2018 * Publicado em: 30/06/2018 